\title{
NGHIÊN CÚU TÍNH TOÁN LAN TRUYỀN MẶN TRÊN SÔNG SÀI GÒN BẰNG PHƯƠNG PHÁP SỐ
}

\author{
Trần Thị Kim ${ }^{1}$ Bùi Hồng Sơn ${ }^{2}$, Nguyễn Thị Bảy ${ }^{3}$, Phùng Thị Mỹ Diễm ${ }^{1}$, Nguyễn Kỳ Phùng ${ }^{4}$
}

Tóm tắt: Trong nhũng năm gần đây, nguồn nườc trên sông Sài Gòn độ mặn ngày càng tăng cao và chưa có xu hướng giảm. Tình trạng thiếu nước, xâm nhập mặn trong mùa khô diê̂n ra ngày càng gay gắt, ảnh hưởng trục tiếp đến hệ thống cấp nước cho TP.HCM. Mặc dù đã chủ động thực hiện nhiều biện pháp nhung các công ty cấp nước vẫn gặp nhiều khó khăn và các nhà máy phải ngung lấy nước thô trong nhiều thời điểm do độ mặn vuợt quy chuẩn cho phép, chi phí vận hành sản xuất nước sạch gia tăng. Theo kết quả khảo sát của Viện Khoa hoc Thủy lợi Miền Nam, tháng 4/2016, tại trạm bơm nước thô Hòa Phú (năm trên sông Sài Gòn thuộc huyện Củ Chi) cho thấy tù cuối tháng 1-2016 đến nay, độ mặn thuoòng xuyên trên nguoơng $150 \mathrm{mg}$ /lit. Nghiên cứu này tập trung vào tính toán và mô phỏng lan truyền mặn một chiều bằng phương pháp số cho hệ thống sông Sài Gòn nhằm hỗ trợ các nhà quản lý đánh giá tác động của xâm nhập mặn đến nông nghiệp và cấp nước.

Từ khóa: Xâm nhập mặn, sông Sài Gòn, phương pháp số, mô hình toán.

Ban Biên tập nhận bài: 08/12/2018 Ngày phản biện xong: 20/01/2019 Ngày đăng bài: 25/03/2019

\section{1. Đặt vấn đề}

Hệ thống sông Sài Gòn - Đồng Nai bao gồm dòng chính sông Đồng Nai và 4 sông nhánh lớn là sông La Ngà, sông Bé, sông Sài Gòn và sông Vàm Cỏ. Xâm nhập mặn là một hiện tượng cực kỳ quan trọng và đáng chú ý hơn cả ở phần hạ lưu sông Sài Gòn - Đồng Nai. Với đặc điểm lòng dẫn sâu, độ dốc đáy sông nhỏ, biên độ triều lớn, do đó nước mặn theo dòng triều xâm nhập rất cao lên thượng lưu vào giữa và cuối mùa khô (tháng 3-4 hàng năm) [9]. Trong vài năm gần đây, cùng với tác động của biến đổi khí hậu và nước biển dâng, sự biến đổi ranh giới xâm nhập mặn trở nên phức tạp. Nước biển dâng kéo theo sự thay đổi biên độ và pha thủy triều trong các vịnh và vùng biển ven bờ [4]. Sự thay đổi này dẫn đến quá trình lan truyền chất trong sông thay đổi theo, đặc biệt là xâm nhập mặn. Do vậy, nhu cầu tính toán và dự báo xâm nhập mặn ngày càng cấp thiết.

${ }^{I}$ Đại học Tài nguyên và Môi truoòng Tp.HCM

${ }^{2}$ Sở Tài nguyên và Môi truoòngTp.HCM

${ }^{3} Đ a i$ hoc Bách Khoa - ĐHQG Tp.HCM

${ }^{4}$ Sở Khoa hoc Công nghệ Tp.HCM

Email:ttkim@hcmunre.edu.vn
Mô hình toán, một phương pháp hiện đại, được phát triển mạnh trong mấy chục năm trở lại đây ở nước ta cũng như trên thế giới. Các mô hình được sử dụng rộng rãi trên thế giới như mô hình HEC-RAS; Mô hình Qual2E của cục bảo vệ môi trường Mỹ (EPA); Mô hình DELFT 3D của Viện Nghiên cứu Thuỷ lực Hà Lan và mô hình Mike 11 của Viện Thuỷ lực Đan Mạch (DHI). Các nghiên cứu tiêu biểu về dòng chảy và chất lượng nước, xâm nhập mặn được thực hiện bởi các tác giả Zheng Chong, Ruibin Zhang, Pawan Kumar Mishra [10, 11, 12]. Theo đó, xu hướng sử dụng các mô hình thương mại vẫn diễn ra tại Việt Nam, có nhiều nghiên cứu về xâm nhập mặn được thực hiện trên hạ lưu hệ thống sông Sài Gòn - Đồng Nai bằng việc sử dụng mô hình toán $[5,7,2]$ tuy nhiên, chi phí sử dụng khá cao và khó khăn khi kết nối hệ thống. Nghiên cứu tính toán lan truyền mặn trên Sông Sài Gòn bằng phương pháp số được đề xuất thực hiện nhằm xây dựng mô hình tính toán và mô phỏng lan truyền mặn một chiều cho một đoạn sông nhất định, như là một công cụ hỗ trợ các nhà quản lý đánh giá tác động của xâm nhập mặn đến sản suất nông nghiệp và nuôi trồng thủy sản tại 
khu vực hạ lưu sông Sài Gòn-Đồng Nai.

\section{Phương pháp nghiên cứu}

\subsection{Nghiên cúu thuật giải của mô hình toán thủy lục [6]}

Mô hình thủy động lực được xây dựng với cơ sở là hệ phương trình Saint-Venan (phương trình liên tục (1) và phương trình động lượng (2)).

Đối với các hàm thông thường nghiệm là một giá trị số (số thực, số phức...). Còn trong phương trình sai phân, mục tiêu là tìm ra công thức của hàm chưa được biết nhằm thỏa mãn mối quan hệ đề ra. Thông thường nó sẽ là một họ các phương trình, sai lệch bằng một hằng số $\mathrm{C}$ nào đó. Hàm này sẽ được xác định chính xác khi có thêm điều kiện xác định ban đầu hoặc điều kiện biên.

Các phương pháp nhằm tìm ra giá trị chính xác của hàm được gọi là phân tích định lượng. Tuy nhiên không phải lúc nào cũng xác định được các giá trị thực, lúc này người ta lại quan tâm đến các giá trị xấp xỉ (có một độ chính xác nhất định) với giá trị thực. Việc tìm các giá trị này được thực hiện thường là bằng phương pháp số với công cụ là máy tính.

Phương trình sai phân được nghiên cứu rộng rãi trong toán học thuần túy và ứng dụng, vật lí và các ngành kỹ thuật.

Phương trình liên tục

Phương trình liên tục được thiết lập dựa trên định luật bảo toàn khối lượng trong một không gian vô cùng bé nằm giữa hai mặt phẳng ướt của kênh.

Phương trình liên tục có dạng:

$$
\frac{\partial Q}{\partial x} d t+B \frac{\partial h}{\partial t} d t=0
$$

Phương trình động lượng

Phương trình động lương có dạng như sau:

$$
\begin{aligned}
& B \frac{\partial z}{\partial t}+\frac{\partial Q}{\partial x}=0 \\
& \frac{\partial Q}{\partial t}+\frac{\partial}{\partial x}\left(\frac{Q^{2}}{A}\right)+g A \frac{\partial z}{\partial x}+g A \frac{Q|Q|}{K^{2}}=0
\end{aligned}
$$

Hệ phương trình (2) được gọi là hệ phương trình Saint-Venant. Phương trình này mô tả sự biến thiên của lưu lượng $\mathrm{Q}$ và mực nước $\mathrm{z}$ hoặc các thông số tương đương theo thời gian và không gian.

\subsection{Nghiên cứu thuật giải của mô hình lan} truyền chất [6]

Phương trình lan truyền chất được viết như sau:

$$
\frac{\partial C}{\partial t}=-U \frac{\partial C}{\partial x}+E \frac{\partial^{2} C}{\partial x^{2}}-K C
$$

Phương trình có thể được viết dưới dạng hoàn thành thể (kết hợp với phương trình liên tục):

$$
\begin{aligned}
& \frac{\partial}{\partial t}(A C)=\frac{\partial}{\partial t}\left(A E \frac{\partial C}{\partial x}\right)-\frac{\partial C}{\partial x}(A U C) \\
& +A(f(C)+G(C))
\end{aligned}
$$

Phương trình đạo hàm riêng phần của quá trình lan truyền chất mô tả sự biến thiên của nồng độ chất theo không gian và thời gian có thể được viết lại như phương trình (5):

$$
\frac{\partial C}{\partial t}+U \frac{\partial C}{\partial x}=E \frac{\partial^{2} C}{\partial x^{2}}-K C+p
$$

Mô hình lan truyên chât sẽ được giải theo phương pháp sai phân hữu hạn bằng sơ đồ Upwind.

\section{Kết quả}

\subsection{Kiểm định mô hình bằng lời giải tích}

\subsubsection{Kiểm định mô hình thủy lực}

Xét sự chuyển động của triều trong kênh kín một đầu và bị phản xạ hoàn toàn tại đầu kín.

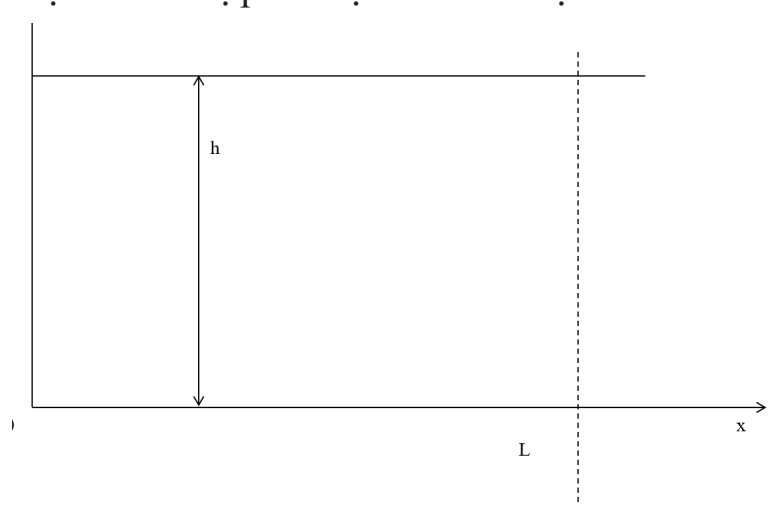

Hình 1. Số hóa đoạn kênh

Dao động mực nước:

$$
z(x, t)=z_{0} \cos (\omega t) \cos (k x)
$$

Tốc độ truyền triều:

$$
u(x, t)=\frac{C_{0}}{h} z_{0} \sin (\omega t) \sin (k x)
$$

Mô hình được áp dụng tính cho đoạn kênh có 
mặt cắt ngang hình chứ nhật, đáy nằm ngang; chiều dài $\mathrm{L}=100 \mathrm{~m}$ (là một bước sóng), độ sâu $\mathrm{h}=1 \mathrm{~m}$.

Điều kiện ban đầu được tính từ phương trình (6) và phương trình (7), tại thời điểm $\mathrm{t}=0$.

Điều kiện biên được áp dụng như sau:

- Tại cuối kênh ( $\mathrm{x}=\mathrm{L})$ cho dao động mực nước dạng: $\mathrm{z}=\mathrm{z} 0 \cos (\omega \mathrm{t})$, với biên đồ triều $\mathrm{z} 0=0.01 \mathrm{~m}$; chu kì $\mathrm{T}=31.927 \mathrm{~s}$; suy ra $(\omega \mathrm{t})=0.1967 \mathrm{rad} / \mathrm{s}$.

- Tại đầu kênh $(\mathrm{x}=0)$ điều kiện phản xạ hoàn toàn cho $\mathrm{Q}=0$.

Kết quả tính toán từ mô hình và nghiệm lý thuyết được trình bày trong hình 2 - 7:

- Hình 2 và hình 3 cho thấy diễn biến theo thời gian của mực nước $\mathrm{z}$ và vận tốc $\mathrm{U}$ tại vị trí $\mathrm{x}=0.5 \mathrm{~L}$

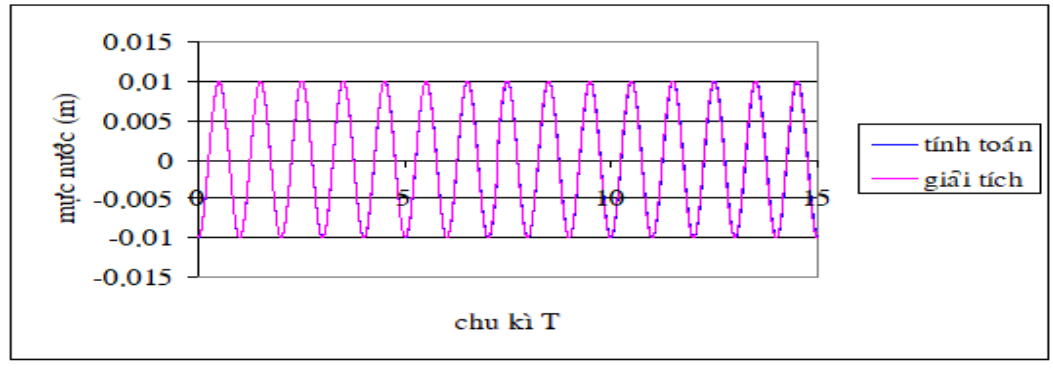

Hình 2. Kết quả mục nước của dòng chảy tại $x=0.5 \mathrm{~L}$

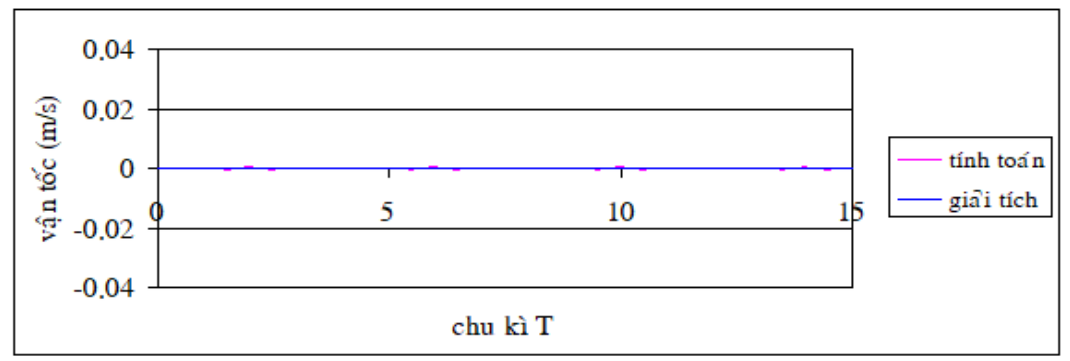

Hình 3. Kết quả vận tốc của dòng chảy tại $x=0.5 \mathrm{~L}$

- Hình 4 và 5 cho thấy diễn biến theo thời gian của mực nước $\mathrm{z}$ và vận tốc $\mathrm{U}$ tại vị trí $\mathrm{x}=0.75 \mathrm{~L}$.

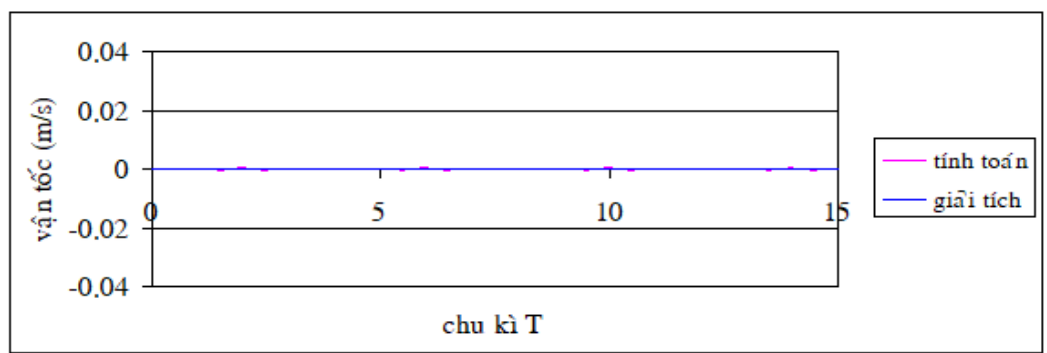

Hình 4. Kết quả mục nước của dòng chảy tại $x=0.75 \mathrm{~L}$

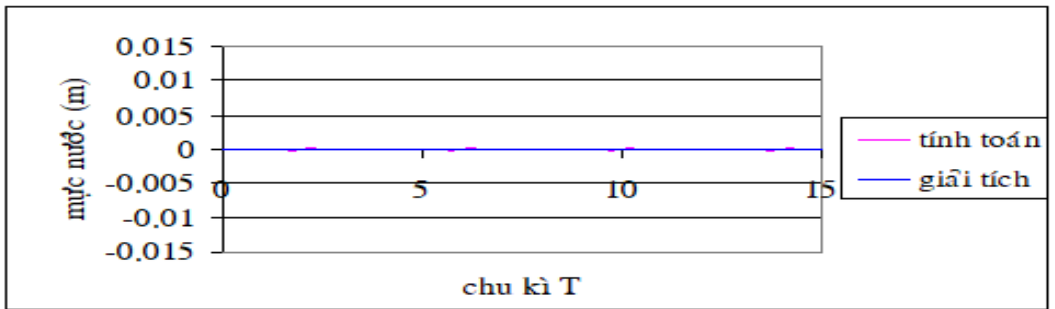

Hình 5. Kết quả vận tốc của dòng chảy tại $x=0.75 \mathrm{~L}$ 


\section{BÀI BÁO KHOA HỌC}

- Hình 6 và 7 cho thấy diễn biến mực nước $\mathrm{z}$ và vận tốc $U$ dọc theo chiều dài kênh được tính tại những nhóm thời điểm khác nhau.

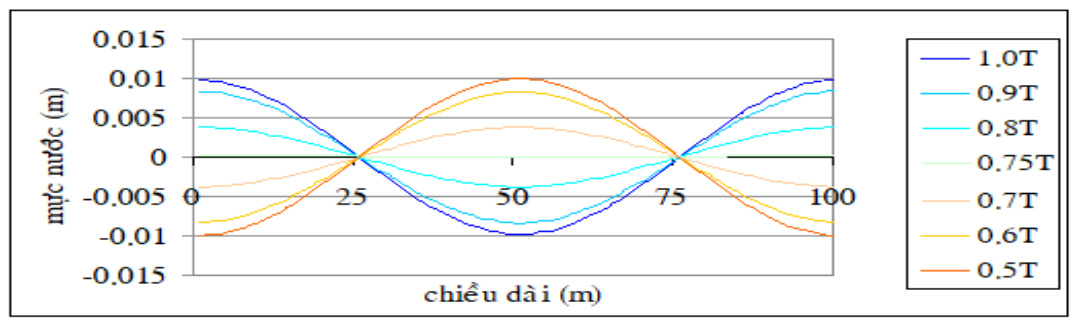

Hình 6. Kết quả mưc nước dọc chiều dài kênh tại nhiều thời điểm

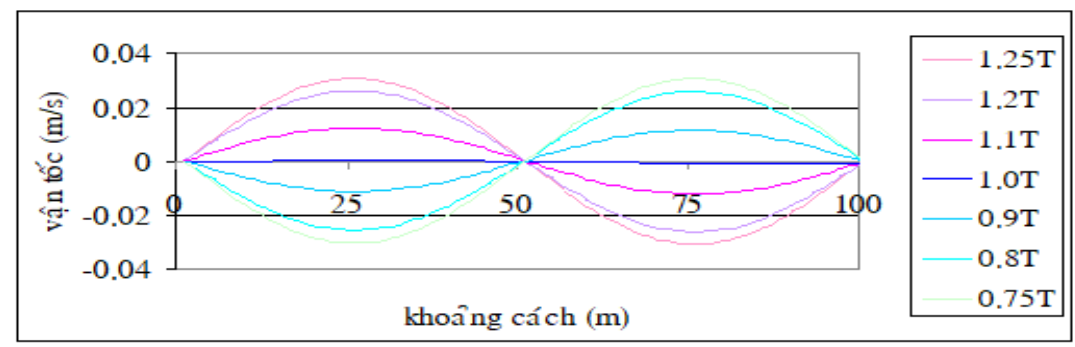

Hình 7. Kết quả vận tốc dọc theo chiều dài kênh tại nhiều thời điểm

Như vậy, mô hình tính đã cho thấy đáp số khá chính xác với nghiệm giải tích, Điều đó đã khẳng định được độ tin cậy của mô hình ít nhất cho những trường hợp đơn giản. từ đây, ta có thể mở rộng áp dụng mô hình tính cho những trường hợp phức tạp hơn với số liệu thực tế.

3.1.2. Kiểm định mô hình lan truyền chất
Ta có, phương trình truyền chất tổng quát:

$$
\frac{\partial}{\partial t}(A C)=\frac{\partial}{\partial x}\left(A E \frac{\partial C}{\partial x}\right)-\frac{\partial}{\partial x}(A U C)+A(f(C)+G(C))
$$

Giải phương trình (8) với những sơ đồ khác nhau: sơ đồ hiện theo Chevereau và Preissmann, sơ đồ ẩn Crank Nicolsion, sơ đồ ẩn Upwind để so sánh với lời giải tích.

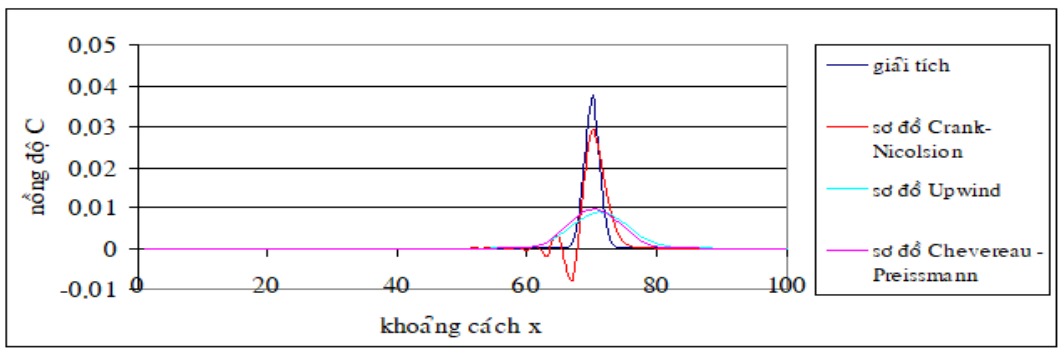

Hình 8. Kết quả nồng độ dọc kênh tại thời điểm $t=700 \mathrm{~s}$

- Các sơ đồ Chevereau-Preissmann và Upwind không làm cho nồng độ chất mang giá trị âm, việc giảm $\Delta \mathrm{t}$ hay $\Delta \mathrm{x}$ trong quá trình chạy thửnghiệm cũng không cho kết quả tốt hơn.

- Ngược lại, đối với sơ đồ Crack Nicolsion, đường biểu diễn nồng độ cho thấy kết quả khá tốt, đặc biệt là tại vị trí $\mathrm{x}=70 \mathrm{~m}$, nồng độ chất đạt cực đại và gần nghiệm giải tích.

Trong nghiên cứu này, nhóm tác giả sử dụng sơ đồ Crank Nicolsion trong chương trình tính mạng sông. Bởi vì trong mô hình tính mạng sông, phương pháp đường đặc trưng được sử dụng để tính nồng độ chất tại hợp lưu trên những nhánh chảy vào hợp lưu và tại biên khi dòng chảy từ miền hướng ra biên. Điều này khắc phục được hiện tượng khuếch tán số.

\subsection{Tiêu chuẩn đánh giá}

Hệ số Nash - Sutcliffe (NSE):

Hệ số hiệu quả Nash-Sutcliffe (NSE): là hệ số tương quan giữa giá trị quan trắc và mô phỏng theo tỷ lệ $1: 1$. 


$$
N S E=1-\frac{\sum_{i=1}^{N}\left(Y_{o b s, i}-Y_{s i m, i}\right)^{2}}{\sum_{i=1}^{N}\left(Y_{o b s, i}-\bar{Y}_{o b s}\right)^{2}}
$$

Hệ số tương quan $\mathrm{R}^{2}$ :

Hệ số tương quan $\mathrm{R}^{2}$ : mô tả mức độ tương quan giữa giá trị mô phỏng và quan trắc. $\mathrm{R}^{2}$ càng tiến đến 1 thì kết quả mô phỏng càng tốt.

Công thức tính hệ số tương quan $\mathrm{R}^{2}$ :

$$
R^{2}=\frac{\sum_{i=1}^{N}\left(Y_{o b s, i}-\bar{Y}_{o b s}\right)\left(Y_{s i m, i}-\bar{Y}_{s i m}\right)}{\left[\sum_{i=1}^{N}\left(Y_{o b s, i}-\bar{Y}_{o b s}\right)\right]^{0.5}\left[\sum_{i=1}^{N}\left(Y_{s i m, i}-\bar{Y}_{s i m}\right)\right]^{0.5}}
$$

\section{3. Úng dụng cho hệ thống sông Sài Gòn-} Đồng Nai

3.3.1. Thiết lập mô hình thủy lực một chiều

a) Thiết lập thông số mô hình thưy lực một chiều

- Dữ liệu tính toán

Vùng tính toán: Vùng tính tính từ sau hồ chứa Dầu Tiếng đến vị trí các cửa sông ven biển Vàm Cỏ, Soài Rạp, Lòng Tàu, Dinh Bà, Thị Vải.

Lưới tính: bao gồm 9 nhánh sông, gồm Sông Sài gòn, sông Đồng Nai, Sông Soài Rạp, Vàm Cỏ, Lòng Tàu, Dinh Bà, Đồng Tranh, Nhà Bè và sông Thị Vải. Khoảng cách $\mathrm{dx}$ lớn nhất trên các nhánh sông là $1000 \mathrm{~m}$ và nhỏ nhất là $100 \mathrm{~m}$. Khoảng cách này được chia chi tiết ở các nhánh sông nhỏ và chia lớn nhất trên các sông lớn nhằm để giảm thời gian tính toán.

- Điều kiện biên

Vị trí các biên được thể hiện chi tiết trong Hình 10. Trong đó:

+ Biên thượng lưu gồm các biên mực nước giờ tại Tân $A n$, Gò Dầu Hạ và biên hồ Trị An và hồ Dầu Tiếng.

+ Biên hạ lưu gồm 4 biên mực nước tại các cửa sông Soài Rạp, Dinh Bà, Lòng Tàu và Thị Vải.

+ Biên cụt: 12 biên lưu lượng với $\mathrm{Q}=0 \mathrm{~m}^{3} / \mathrm{s}$

- Điều kiện ban đầu
Điều kiện ban đầu: Giả sử thời điểm ban đầu nước tĩnh, $\mathrm{Q}=0 \mathrm{~m}^{3} / \mathrm{s}$.

Điều kiện mực nước ban đầu bằng 0 và ở hợp lưu bằng $0 \mathrm{~m}$.

b) Dũ liệu tính toán hiệu chỉnh mô hình

Thời gian tính: từ ngày 01/04/2013 12:00 đến 30/04/2013 00:00 để hiệu chỉnh mô hình; sử dụng bước thời gian là 15 giây. Trạm sử dụng hiệu chỉnh là Cát Lái, Nhà Bè và Phú An với bộ số liệu đo đạc mực nước từ 26/04/2013 9:00 đến 28/04/2013 20:00.

Hệ số nhám: Thay đổi từ 0.02-0.04.

Nguồn cơ sở dữ liệu thu thập cho tính toán được trình bày trong Bảng 1 sau:

\begin{tabular}{|c|c|c|}
\hline Dũ liệu & Nguồn & Mô tả dữ liệu \\
\hline \multicolumn{2}{|l|}{ Mực nước } & Mực nước các \\
\hline tại Vũng & IMHOEN & trạm Vàm Cỏ, \\
\hline Tàu, Vàm & Đài Khí tượng & Dinh bà, Lòng \\
\hline \multirow{2}{*}{$\begin{array}{l}\text { Kênh và } \\
\text { các trạm }\end{array}$} & Thủy văn & Tàu, Soài Rạp, \\
\hline & Nam Bộ & Thị Vải (3 trạm), \\
\hline \multicolumn{2}{|l|}{ hiệu chỉnh } & Biên Hòa. \\
\hline \multirow{5}{*}{$\begin{array}{c}\text { Mặt cắt } \\
\text { ngang sông }\end{array}$} & \multirow{5}{*}{$\begin{array}{l}\text { SIWRR } \\
\text { Viện Thủy } \\
\text { Lợi Miền } \\
\text { Nam, } \\
\text { IMHOEN }\end{array}$} & Số liệu mặt cắt \\
\hline & & ngang $\mathrm{s}$ \\
\hline & & (Sông Sài Gòn, \\
\hline & & Đồng Nai, Dinh \\
\hline & & Bà, ...) \\
\hline Số liệu xả & Ban quản trị & \\
\hline hồ Trị An, & Hồ Dầu & Lưu lượng xả \\
\hline Dầu Tiếng & Tiếng, Trị An & \\
\hline
\end{tabular}

Bảng 1. Cơ sở dĩ liệu

c) Hiệu chỉnh và kiểm định mô hình

- Hiệu chỉnh mô hình thủy lực:

Kết quả mực nước thực đo và mực nước tính toán được thể hiện như Hình $9-11$ : 


\section{BÀI BÁO KHOA HỌC}

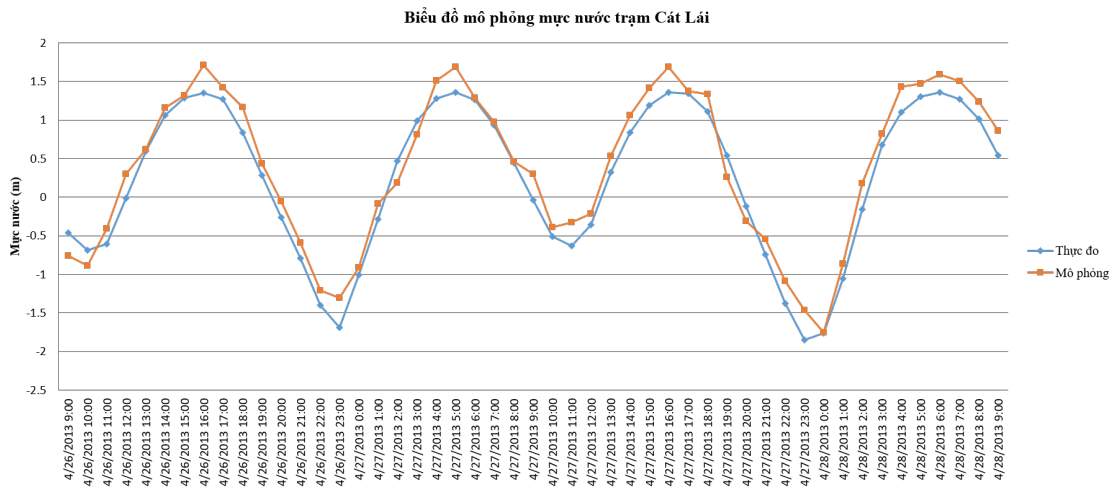

Hình 9. Biểu đồ mưc nuoóc trạm Cát Lái tù̀ 26/04/2013 9:00 đến 28/04/2013 20:00

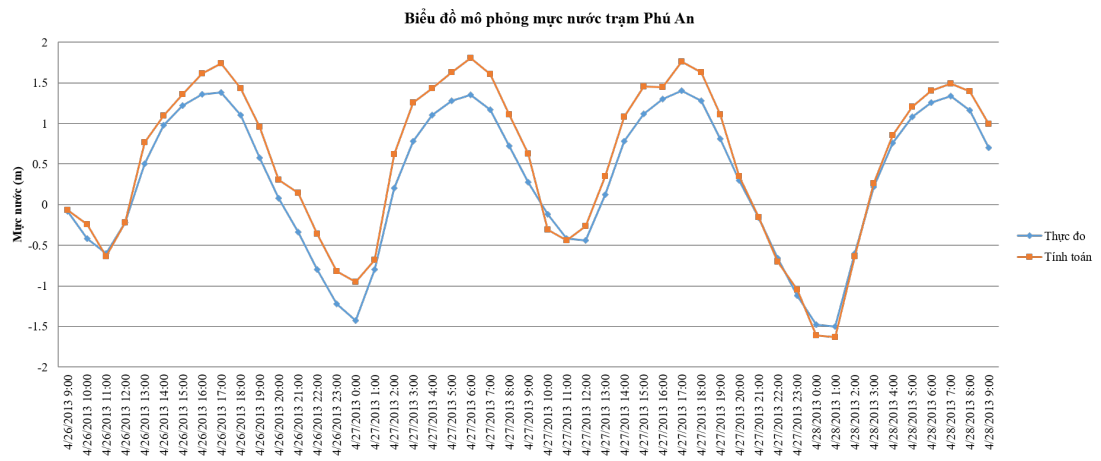

Hình 10. Biểu đồ mưc nước trạm Phú An tì 26/04/2013 9:00 đến 28/04/2013

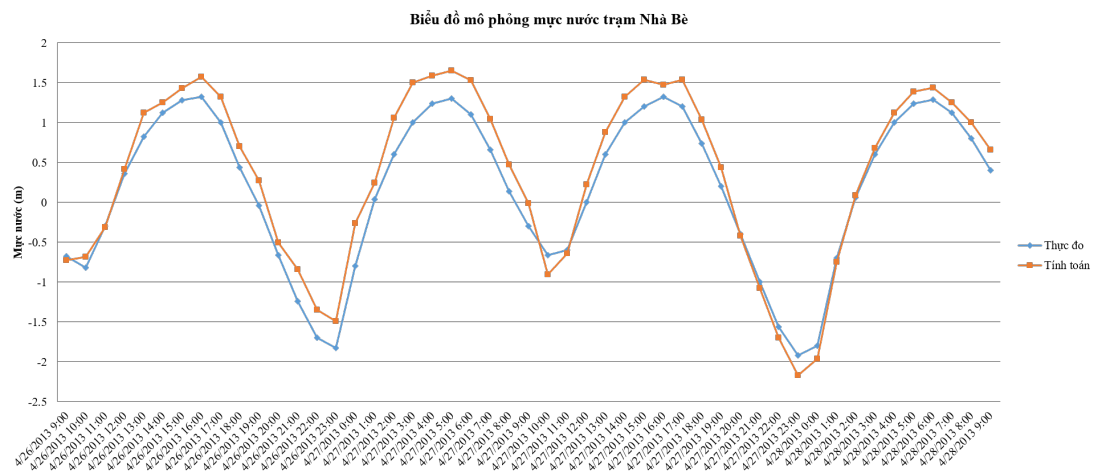

Hình 11. Biểu đồ mưc nước trạm Nhà Bè tù 26/04/2013 9:00

Sử dụng các hệ số thống kê RSR, R², NSE để dánh giá hiệu quả mô hình được trình bày trong Bảng 2:

Bảng 2. Chỉ số đánh giá mô hình hiệu chỉnh thuy lucc

\begin{tabular}{cccc}
\hline Trạm & RSR & $\mathrm{R}^{2}$ & NSE \\
\hline Cát Lái & 0,239 & 0,967 & 0,942 \\
Nhà Bè & 0,272 & 0,975 & 0,925 \\
Phú An & 0,313 & 0,901 & 0,970 \\
\hline
\end{tabular}

Như vậy, kết quả tính toán tương đối phù hợp với kết quả thực đo, chỉ số NSE và $\mathrm{R}^{2}$ ở các trạm đều cao hơn 0,8 , chỉ số RSR đều nhỏ hơn 0,5 .

- Kiểm định mô hình thủy lực:

Thời gian kiểm định từ 09:00 ngày 25/05/2013 đến 08:00 ngày 27/5/2013. Sử dụng số liệu mực nước và lưu lượng thực đo các trạm Cát Lái, Phú An, Nhà Bè.

Kết quả mực nước thực đo và tính toán được trình bày như Hình 12 - 14: 


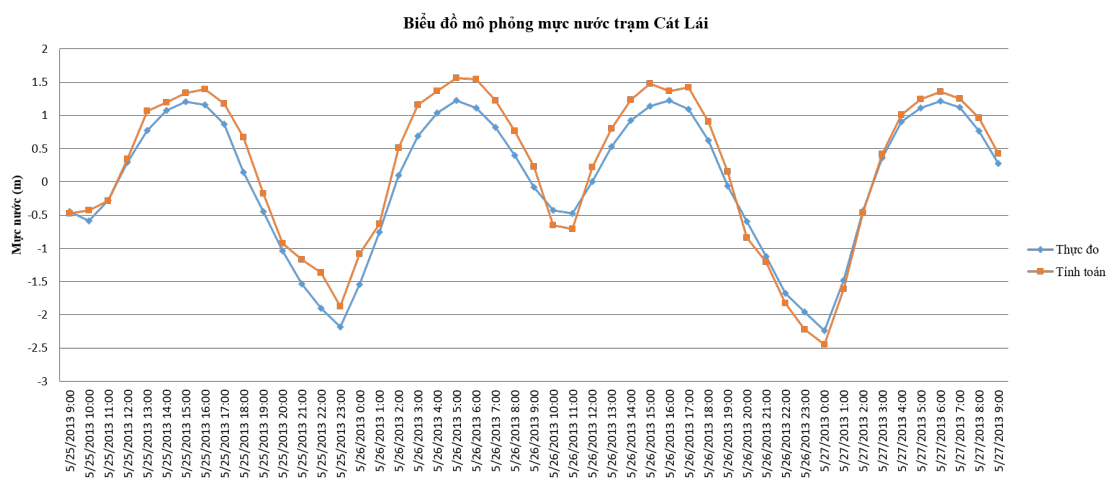

Hình 12. Biểu đồ mực nước trạm Cát Lái tù̀ 09:00 ngày 25/05/2013 đến 08:00 ngày 27/05/2013

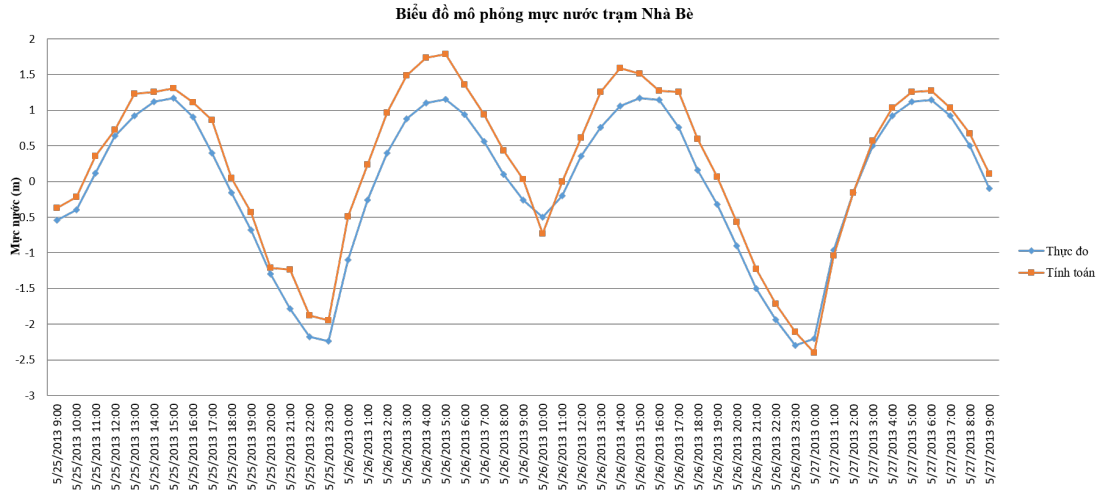

Hình 13. Biểu đồ mực nước trạm Nhà Bè tù̀ 09:00 ngày 25/05/2013 đến 08:00 ngày 27/05/2013

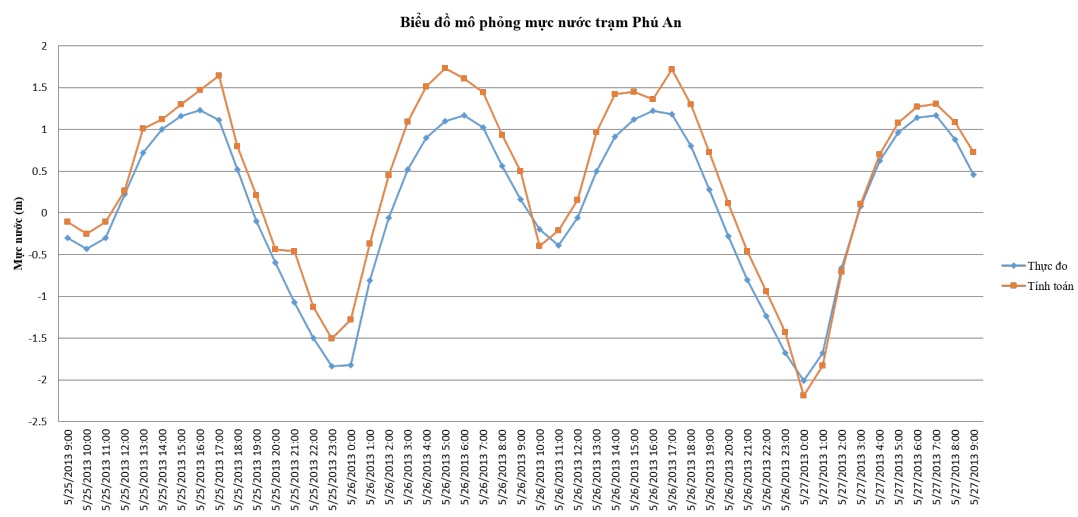

Hình 14. Biểu đồ mục nước trạm Phú An tù̀ 09:00 ngày 25/05/2013 đến 08:00 ngày 27/05/2013

Bảng 3. Chỉ số đánh giá mô hình kiểm định thuy lục

\begin{tabular}{cccc}
\hline Trạm & RSR & $\mathrm{R}^{2}$ & NSE \\
\hline Cát Lái & 0,36 & 0,96 & 0,86 \\
Nhà Bè & 0,31 & 0,96 & 0,89 \\
Phú An & 0,36 & 0,96 & 0,86 \\
\hline
\end{tabular}

Các chỉ số thống kê kiểm định mô hình được trình bày trong Bảng 3 :

Từ kết quả trên, nhóm tác giả đã đưa ra bộ thông số nhám sẽ được dùng để tính toán kiểm định thủy lực được trình bày như trong Bảng 4 : 


\section{BÀI BÁO KHOA HỌC}

Bảng 4. Hệ số nhám trên các sông trong khu vục Tp.HCM sau khi hiệu chỉnh

\begin{tabular}{cc}
\hline Tên sông & Hệ sô Manning \\
\hline Đồng Nai & 0,032 \\
Sài Gòn & 0,035 \\
Nhà Bè & 0,035 \\
Lòng Tàu & 0,027 \\
Dinnh Bà & 0,028 \\
Đồng Tranh & 0,021 \\
Thị Vải & 0,021 \\
Vàm Cỏ & 0,027 \\
Soài Rạp & 0,029 \\
\hline
\end{tabular}

3.3.2. Thiết lập mô hình lan truyền mặn

a) Thiết lập thông số mô hình lan truyền mặn

Bộ số liệu nồng độ tại trạm Cát Lái và Phú An từ ngày 24/04/2013 00:00 đến 30/04/2013 00:00 để hiệu chỉnh mô hình (IMHOEN, Đài Khí tượng Thủy Văn Nam Bộ).

Các trạm hiệu chỉnh mô hình: Sử dụng 2 trạm đo mặn từ số liệu đo đạc của Đài Khí tượng là Cát Lái và Phú An từ 24/04/2013 00:00 đến 23:00 26/04/2013 00:00 để hiệu chỉnh mô hình.

Bộ dữ liệu mặn: được thu thập tại Đài Khí tượng Thủy văn Nam Bộ tại trạm Cát Lái và Nhà Bè từ ngày 24/04/2013 00:00 đến 30/04/2013 00:0

\section{b) Vùng tính và lưới tính}

Vùng tính và lưới tính lan truyền mặn giống với vùng tính của mô hình thủy lực.

c) Điều kiện biên và điều kiện ban đầu

- Điều kiện biên mặn

Biên mặn lấy giống biên thủy lực, trong đó, các biên thượng lưu lấy bằng $0.1 \mathrm{~g} / 1$, biên hạ lưu lấy từ $28-33 \mathrm{~g} / 1$.

\section{- Điều kiện ban đầu}

Do độ mặn bị ảnh hưởng bởi điều kiện ban đầu rất lâu nên điều kiện ban đầu được lấy dựa theo chiều dài của con sông tang dần lên thượng nguồn.Bước thời gian sử dụng trong mô hình là 30 giây.

d) Hiệu chỉnh và kiểm định mô hình lan truyền mặn

- Hiệu chỉnh mô hình

Hệ số khuếch tán lấy chung cho các đoạn sông là $5-25 \mathrm{~m}^{2} / \mathrm{s}$. Tiến hành mô phỏng xâm nhập mặn và trích xuất dữ liệu để phục vụ hiệu chỉnh tại 2 trạm đo: Cát Lái và Phú An. Kết quả biểu diễn kết quả mặn thực đo và mặn tính toán được trình bày trong Hình 15 và 16 sau:

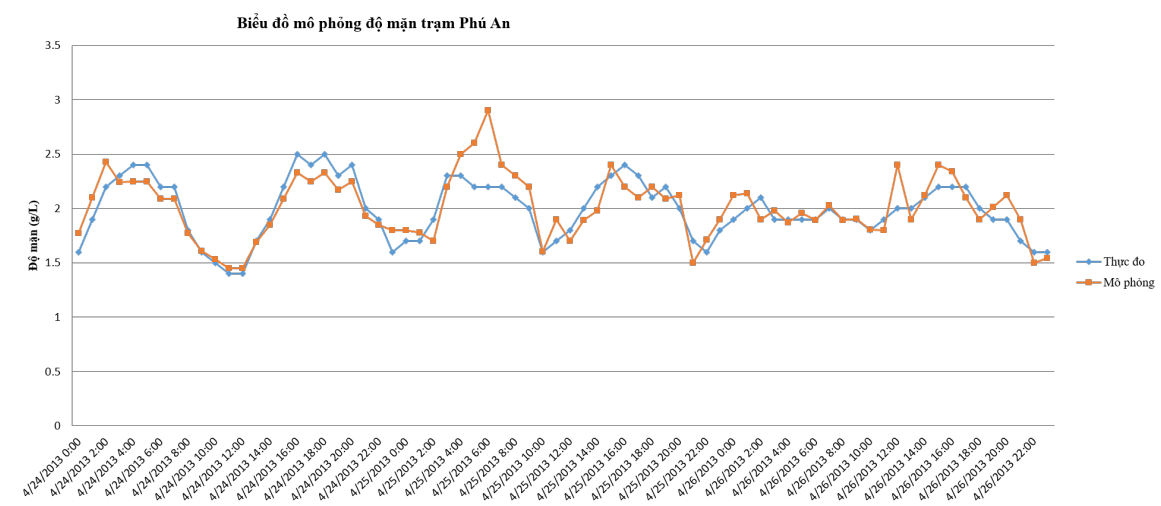

Hình 15. Biểu đồ độ mặn trạm Phú An tù 0:00 ngày24/4 đến 23:00 26/4/2013 


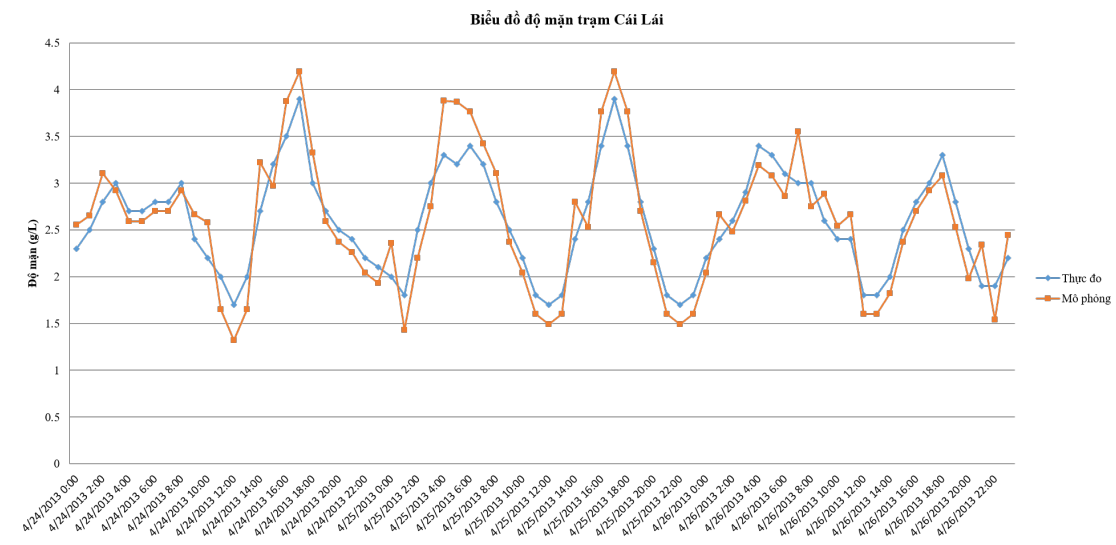

Hình 16. Biểu đồ độ mặn trạm Cát Lái tù̀ 0:00 ngày24/4 đến 23:00 26/4/2013

Bảng 5. Các chỉ số thống kê sau hiệu chỉnh mạn

\begin{tabular}{cccc}
\hline Trạm & RSR & $\mathrm{R}^{2}$ & NSE \\
\hline Cát Lái & 0,5 & 0,87 & 0,75 \\
Phú An & 0,67 & 0,67 & 0,611 \\
\hline
\end{tabular}

Kết quả tính toán tương đối phù hợp với kết quả quan trắc, chỉ số NSE và $\mathrm{R}^{2}$ ở các trạm đều cao hơn 0.6. Hệ số RSR nhỏ hơn 0.7. Do vậy, bộ thông số khuếch tán sẽ được dùng để tính toán kiểm định mặn (Bảng 6).

Bảng 6. Hệ số khuếch tán cho mô hình lan truyền mặn các sông nội tỉnh Tp.HCM

\begin{tabular}{cc}
\hline Tên sông & Hệ sô khuếch tán \\
\hline Đồng Nai & 25 \\
Sài Gòn & 25 \\
Nhà Bè & 25 \\
Lòng Tàu & 21 \\
Dinh Bà & 22 \\
Đồng Tranh & 17 \\
Thị Vải & 17 \\
Vàm Cỏ & 24 \\
Soài Rạp & 20 \\
\hline
\end{tabular}

- Kiểm định mô hình

Sử dụng số liệu mặn thực đo tại 3 trạm đo từ ngày 15/04/2016 1:00 đến ngày 17/4/2016 23:00 để kiểm định.

Kết quả mặn thực đo và mặn tính toán được biểu diễn như trong Hình 17 - 19:

Các chỉ số đánh giá mô hình được trình bày trong Bảng 7:

Bảng 7. Các chỉ số thống kê sau kiểm định mặn

\begin{tabular}{cccc}
\hline Trạm & RSR & $\mathrm{R}^{2}$ & NSE \\
\hline Cát Lái & 0,47 & 0,8665 & 0,7502 \\
Phú An & 0,45 & 0,6157 & 0,4454 \\
Thủ Thiêm & 0,48 & 0,71 & 0,532
\end{tabular}

Như vậy, kết quả tính toán tương đối phù hợp với kết quả quan trắc, chỉ số NSE và $\mathrm{R}^{2}$ ở các trạm đều cao hơn 0,6 , kết quả ở mức chấp nhận được. 


\section{BÀI BÁO KHOA HỌC}

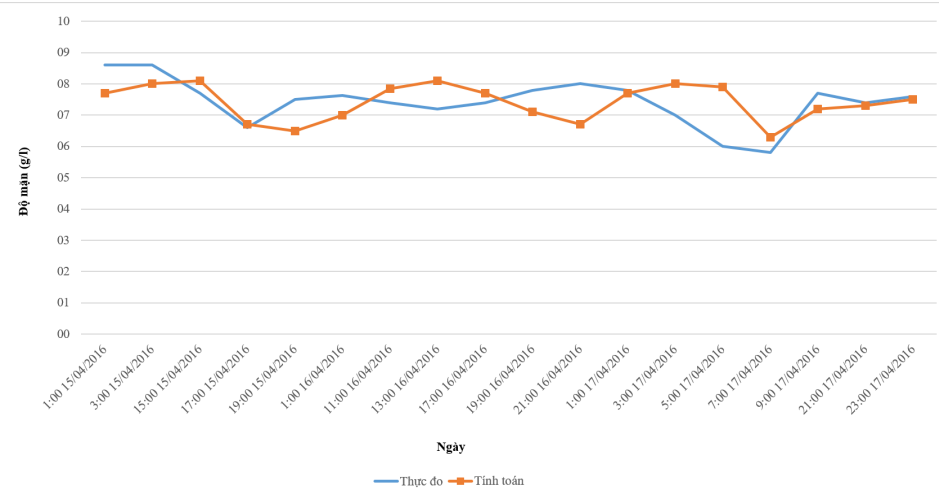

Hình 17. Biểu đồ độ mặn trạm Cát Lái tù 1:00 ngày 15/04/2016 đến 23:00 ngày 17/04/2016

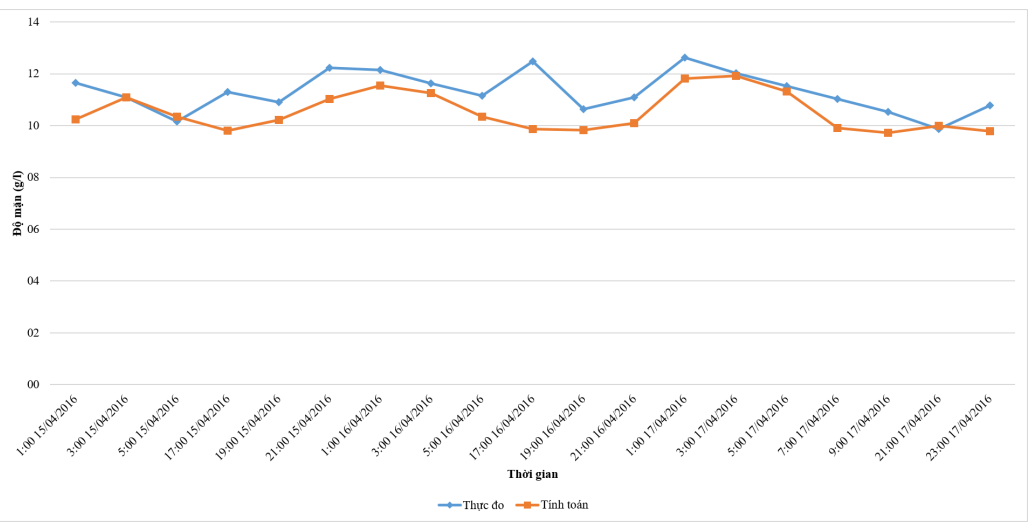

Hình 18. Biểu đồ độ mặn trạm Nhà Bè tù 1:00 ngày 15/04/2016 đến 23:00 ngày 17/04/2016

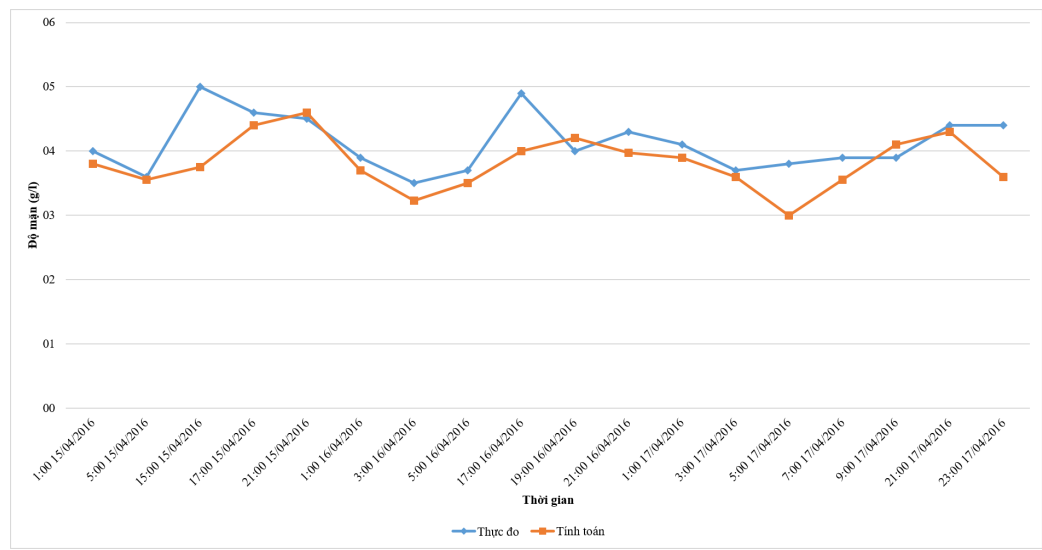

Hình 19. Biểu đồ độ mặn trạm Thủ Thiêm tù 1:00 ngày 15/04/2016 đến 23:00 ngày 17/04/2016

\subsection{3. Đánh giá diễn biến xâm nhập mặn tại} khu vưc TP.HCM

Diễn biến mặn trên các sông tỉnh Đồng Nai, TP. Hồ Chí Minh phần lớn phụ thuộc vào chế độ triều cường trên hai vùng tính sau đây: (1) Sông Sài Gòn, Nhà bè và sông Đồng Nai chịu ảnh hưởng của chế độ triều cường từ vịnh Đồng Tranh.
(2) Sông Đồng Tranh, sông Gò Gia, sông Thị Vải, Vàm Cỏ, Soài Rạp, Lòng Tàu, Dinh Bà chịu ảnh hưởng bởi chế độ triều cường từ vịnh Gành Rái.

Kết quả mô phỏng xâm nhập mặnvào năm 2016, cho thấy:

RGM 1: RGM $1(0,25 \%)$ là vùng an toàn cho cấp nước sinh hoạt trên các sông nội tỉnh 


\section{Đồng Nai- TP.HCM}

Trên nhánh Sông Sài Gòn, RGM 1 cách vị trí cách trạm Phú An một khoảng 12,19km (về phía thượng lưu).

RGM 2: RGM 2 (0,5\%)được đánh giá để xác định vùng cho phép cấp nước sinh hoạt (qua xử lý thông thường), bảo tồn thực vật thủy sinh và các mục đích khác có yêu cầu chất lượng nước tương tự với độ mặn $0,25-0,5 \%$.

Trên nhánh Sông Sài Gòn, RGM 2 cách vị trí trạm Phú An một khoảng 8,27 km (về phía thượng lưu).

RGM 3: RGM 3 (1\%) được đánh giá để xác định vùng cho phép sử dụng nước với mục đích tưới tiêu thủy lợi hoặc các mục đích sử dụng khác có yêu cầu chất lượng nước tương tự với độ mặn 0,5 - 1\%o.

Trên nhánh Sông Sài Gòn, RGM 3 cách vị trí cách trạm Phú An một khoảng 4,6 km (về phía thượng lưu).

RGM 4 (2\%): Chất lượng nước ứng với độ mặn cho phép trong khoảng từ $1 \%$ - $2 \%$ ocó thể phụcvụ tốt cho nuôi trồng thủy sản nước lợ, tuy nhiên, giảm năng suất cây trồng nhạy cảmmặn.

Trên nhánh Sông Sài Gòn, RGM 4 cách vị trí trạm Phú An một khoảng là 3,9km (về phía hạ lưu)

RGM 5 (4\%o): Chất lượng nước ứng với độ mặn cho phép trong khoảng từ $2 \%$ - $4 \%$ có thể phục vụ tốt cho nuôi trồng thủy sản nước lợ, tuy nhiên, giảm năng suất nhiều loại cây trồng.

Trên nhánh sông Sài Gòn, RGM 5 cách vị trí trạm Phú An khoảng 9,1 km về phía hạ lưu.

RGM 6 (8\%): Chất lượng nước ứng với độ mặn cho phép trong khoảng từ $4 \% 0-8 \%$ : Chỉ phục vụnuôi trồng một số loại thủy sản nước lợ, tuy nhiên, giảm năng suất các cây trồng chịu mặn.

Tại nhánh Sông Nhà Bè, RGM 6 tại vị trí ngay tại trạm Nhà Bè.

RGM 7 (18\%): Chất lượng nước ứng với giá

Lời cảm ơn: Nghiên cứu nằm trong khuôn khổ đề tài "Nghiên cứu bộ chuẩn SWE (Sensor Web Enablement) của OGC và áp dụng thử nghiệm xây dựng các hệ thống mạng luới quan trắc độ mặn theo tiêu chuẩn mở quốc tế"”. trị độ mặn từ 8 - 18\%o có thể phục vụ nuôi trồng một số loài thủy sản nước lợ nhưng không tưới tiêu được.

- Tại nhánh Soài Rạp, RGM 7 cách trạm Nhà Bè một đoạn khoảng 13,8 km về phía hạ lưu.

- Tại nhánh Lòng Tàu, RGM 7 cách trạm Nhà Bè một đoạn khoảng 18,05 km về phía hạ lưu.

- Tại nhánh Đồng Tranh, RGM 7 cách trạm Nhà Bè 1 đoạn khoảng 14,61 km về phía hạ lưu.

Thấy được rằng từ cửa sông Soài Rạp, Vàm Cỏ, Dinh Bà, Lòng Tàu, Thị Vải trở vào nội đồng, độ mặn giảm dần. Tại khu vực cửa sông có độ mặn lớn nhất >18 g/L. Khu vực có độ mặn nhỏ nhất đó là khu vực Sông Sài Gòn (cửa xả Hồ Dầu Tiếng) với độ mặn nhỏ chỉ khoảng $0,05 \mathrm{~g} / \mathrm{l}$.

\section{Kết luận}

Bài báo "Nghiên cứu tính toán lan truyền mặn trên sông Sài Gòn bằng phuoong pháp số" đã cho thấy mô hình một chiều vừa được thiết lập tính toán xâm nhập mặn khá tốt với kết quả đáng tin cậy. Ranh mặn $0,5 \%$ (vùng cho phép cấp nước sinh hoạt qua xử lý thông thường, bảo tồn thực vật thủy sinh và các mục đích khác cách vị trí trạm Phú An một khoảng 8,27 km (về phía thượng lưu). Trên nhánh sông Sài Gòn,trạm Phú An cách ranh mặn dùng được mục đích tưới tiêu thủy lợi (1\%o) một khoảng 4,6 km về phía thượng lưu và cách ranh mặn phục vụ cho mục đích nuôi trồng thủy sản là khoảng $3,9 \mathrm{~km}$ về phía hạ lưu. Độ mặn cao nhất tại ranh mặn 18\%o, ở đây có thể phục vụ nuôi trồng mộtsố loài thủy sản nước lợ nhưng không tưới tiêu được.Tại nhánh Soài Rạp, RGM 18\%o cách trạm Nhà Bè một đoạn khoảng 13,8 km về phía hạ lưu.Tại nhánh Lòng Tàu, RGM 18\% cách trạm Nhà Bè một đoạn khoảng 18,05 km về phía hạ lưu.

Kết quả của nghiên cứu này là nghiên cứu tiền đề cho việc xây dựng hệ thống quan trắc và cảnh báo xâm nhập mặn theo tiêu chuẩn mở quốc tế. 


\section{BÀI BÁO KHOA HỌC}

\section{Tài liệu tham khảo}

1. Đậu Văn Ngọ (1998), Nghiên cứu sự dịch chuyển ranh giới nhiễm mặn ở hạ lưu sông Đồng Nai khi xuất hiện các công trình thủy công, Báo cáo Khoa học Hội nghị Khoa học ĐCCT toàn quốc với sự công nghiệp hóa và hiện đại hóa đất nước, Quyển 1, tr. 155- 161.

2. Đậu Văn Ngọ (2007), Tính toán xâm nhập mặn hệ thống sông Đồng Nai, Tạp chí Địa chất.

3. Lê Song Giang, Vũ Linh Diệu (2011), Thuỷ triều khu vưc ven biển Nam bộ trong điều kiện nước biển dâng, Tuyển tập công trình Hội nghị Co học Thủy khi Toàn quốc năm 2011, Cửa Lò, ngày 21 - 23 / 7/ 2011.

4. Le Song Giang (2011), Building computational models for integrated urban drainage calculations, The summary report the results of scientific and technological themes available HCM city - Vietnam Nation University, November, 2011

5. Lê Ngọc Bích, Nguyễn Như Khuê (1995), Nghiên cưu ảnh hưởng công trình thượng nguồn (Trị An, Thác Mo, Phước Hòa, Dầu Tiếng) đến hạ du sông Sài Gòn, Đề tài NCKH cấp Nhà nước.

6. Lieou Kiến Chính, Trần Thị Kim, Nguyễn Thị Bảy (2016), Mô hình toán tính sạt lở bò̀ theo co chế trượt xoay, Tạp chí Khoa học và công nghệ - Đại học Đag Nẵng, Số 3, Tr.9-13.

7. Nguyễn Ân Niên, Đỗ Tiến Lanh (1995), Nghiên cưu ảnh huoởng của các công trình thuợng nguồn (Dầu Tiếng, Trị An, Thác Mo', Phước Hoà) đến vùng hạ du sông Đồng Nai-Sài Gòn, Viện Khoa học Thủy lợi miền Nam.

8. Lê Anh Tuấn, Lê Quang Trí, Nguyễn Hiếu Trung, Lê Văn Dũ, Văn Phạm Đăng Trí (2012). Dự án nâng cao khả năng chống chịu của thành phố cần tho để ứng phó với xâm nhập mặn do biến đổi khí hậu gây ra Hợp phần 3: Xác định các ngương xâm nhập mặn và hành động úng phó. Văn phòng công tác biến đổi khí hậu thành phố Cần Thơ (CCCO), 8/2012.

9. Viện Quy hoạch Thủy lợi miền Nam (2012), Nghiên cưu lập quy trình điều hành hệ thống liên hồ chứa trên lưu vực sông Đồng Nai-Sài Gòn nhằm chống ngập úng cho khu vực thành phố Hồ Chí Minh. Mã số: ĐTĐL.2009T/01, 2012.

10. Doan Quang Tri, Nguyen Cao Don, Chen Yi Ching và Pawan Kumar Mishra (2014). Modeling the influence of river flow and salinity intrusion in the MeKong river estuary VietNam. Lowland Technology International, Vol.16, 14-25.

11. RuibinZhang, XinQian, HuimingLi, XingchengYuan, RuiYe (2012). Selection of optimal river water quality improvement programs using QUAL2K: A case study of Taihu Lake Basin, China. Science of the total Environment, Vol.431, 278-285.

12.Zheng Chong, Yang Wei, Yang Zhifeng (2010). Environmental flow management strategies based on the spatial distribution of water quality, a case study of Baiyangdian Lake, a shallow freshwater lake in China. Procedia Environmental Sciences, Vol.2, 896-905. 


\title{
THE CALCULATION OF SALINIZATION BY NUMERICAL METHOD: A CASE STUDY FOR SAI GON RIVER
}

\author{
Tran Thi Kim¹, Bui Hong Son², Nguyen Thi Bay², \\ Phung Thi My Diem ${ }^{1}$, Nguyen Ky Phung ${ }^{4}$ \\ ${ }^{1} \mathrm{HCMC}$ University of Natural Resources and Environment \\ ${ }^{2}$ HCMC Department of Natural Resources and Rnvironment \\ ${ }^{3}$ University of Technology \\ ${ }^{4}$ Department of Science and Technology, HCMC
}

\begin{abstract}
It is true that the salinity of the Saigon River has increased in considerably recent years. Thelack of water and saline intrusion in the drought season have become increasingly serious, directly affecting the water supply system for Ho Chi Minh City. Although the authorities have actively implemented many solutions, the water supply companies still face many difficulties and even stop taking raw water for many times due to salinity exceeding the permitted standards. According to the survey results of the Southern Institute of Water Resources Research, salinity at the Hoa Phu raw water pumping station (located on the Saigon River in Cu Chi district) was above 150 $\mathrm{mg} /$ liter from the end of January to April 2016. For the reasons mentioned above, this study focuses on calculating and simulating a one-way salt transmission by numerical method for the Saigon River in order to support for managers to assess the impact of saltwater instrusion into agriculture and supplying water.
\end{abstract}

Keywords: Salinization, Saigon River, numerical method, modelling. 